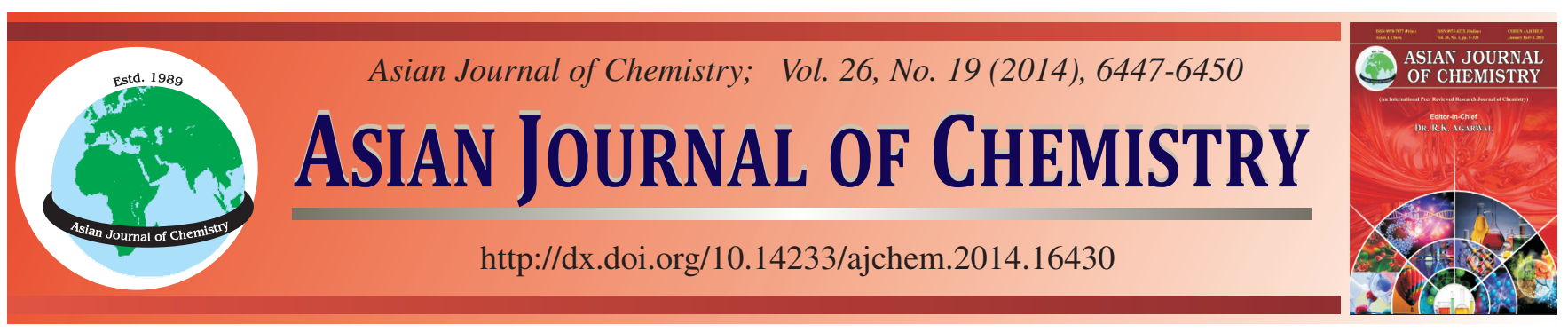

\title{
Preparation of Poly(erythrosine) Modified Electrode and Its Application in Determination of Catechol
}

\author{
Qiang Xu, Yue Hua, Jia-Hong He, Wu-Quan Ding and Zong-Rong Song*
}

School of Materials and Chemical Engineering, Chongqing University of Arts and Sciences, Chongqing 402160, P.R. China

*Corresponding author: E-mail: xuq18@sina.com

A poly(erythrosine) chemical modified electrode (P-Ery/GCE/CME) was fabricated by electrochemical immobilization of erythrosine on a glassy carbon electrode through cyclic voltammetry. The modified electrode had good electrocatalytic oxidization function to catechol and it significantly increased the catechol oxidation peak currents. The effect of acidity of electrolytes and scan rates on electrocatalytic oxidization function of the P-Ery/GCE/CME of catechol was also studied. The linear response were obtained in the range of $6 \times 10^{-6}$ to $7 \times 10^{-4} \mathrm{~mol} / \mathrm{L}$ and the detection limit was $8 \times 10^{-7} \mathrm{~mol} / \mathrm{L}$ for catechol. The modified electrode has exhibited satisfactory stability and selectivity and strong antiinterference. It was successfully used to determine catechol in wastewater samples with recoveries between 99.1 and $103.2 \%$.

Keywords: Poly(erythrosine) modified electrode, Catechol, Electrocatalytic.

\section{INTRODUCTION}

Catechol (CAT) is an important organic chemical raw materials and used in rubber, pharmaceuticals, pesticides, dyes, photographic materials, spices and other industries of basic organic ingredients or intermediates. Because of catechol of the high toxicity and low degradation, there is a large toxicity for organ ${ }^{1-3}$ and an environmental pollutant ${ }^{4}$. Therefore, it is important to establish a rapid, simple, sensitive and accurate method for the determination of catechol. Several methods for the determination of phenolic compunds are $\mathrm{HPLC}^{5,6}$ gas chromatography, spectrophotometry ${ }^{7}$. However, these methods are mostly procedures cumbersome, time-consuming and most of them required expensive large equipment. Compared with other methods, electrochemical methods have been received great attentions due to its simple, rapid, low cost and high sensitivity.

Recently, polymer film modified electrode in chemical sensors is concerned. Electro-polymerization in the determination and analysis of substances has many advantages, because the electrochemical deposition of the polymer is strongly adsorbed on the electrode surface to form a stable polymer film, which has a fine sensitivity, selectivity and uniformity ${ }^{8-10}$. The molecular structure of the polymer organic of dye has a large $\pi$-conjugated system to be conducive to adsorption of molecules on the electrode surface, the molecule itself has excellent electrochemical activity and is a better medium body ${ }^{11}$. In this paper, poly(erythrosine) modified electrode is prepared by polymerization of erythrosine into glassy carbon electrode; determination of catechol modified electrode has effective catalytic activity. This modified electrode can be used to simulate the determination of catechol in water samples. Currently, erythrosine not been used in modified electrode.

\section{EXPERIMENTAL}

Erythrosine (Ery) was obtained from Tianjin Guangfu Fine Chemical Research Institute (China), catechol and other analytical chemicals were purchased from the Sinopharm Chemical Reagent Co. Ltd (China. $0.10 \mathrm{~mol} / \mathrm{L}$ phosphate buffered solution (PBS, $\mathrm{NaOH}-\mathrm{KH}_{2} \mathrm{PO}_{4}$ ) was prepared in our laboratory.

Electrochemical experiments were recorded on LK2005 A Electrochemical Workstation. Acidity adjustment were obtained from a PHS-3C pH meter and Cleaning of the electrode were deal with a KQ 3200 E ultrasonic cleaner.

Preparation of copper doped poly(erythrosine)/GCE/ CME modified electrode: $\mathrm{GCE}(\Phi=3 \mathrm{~mm})$ was polished on a wet metallographic sand paper (size 1000) and then was sequentially polished with 0.3 and $0.05 \mu \mathrm{m}$ alumina/water slurry on a polishing cloth to a mirror-like finish, followed by sonication and then rinsed with distilled water. 
The treated GCE was immersed in PBS buffer solution containing $1 \times 10^{-3} \mathrm{~mol} / \mathrm{L}$ erythrosine and subjected to $\mathrm{CV}$ in the range of $-0.8-2.3 \mathrm{~V}$ at a scan rate of $100 \mathrm{mV} / \mathrm{s}$ for 10 cycles. P-Ery /GCE/CME modified electrode was cleaned with distilled water and ready to use the determination of catechol.

General procedure: All electrochemical experiments were carried out at LK2005 A electrochemical workstation. A conventional three-electrode system was used where glassy carbon electrode or P-Ery/GCE/CME, a platinum wire and an $\mathrm{Ag} / \mathrm{AgCl}$ electrode were used as working, counter and reference electrodes, respectively. Cyclic-voltammetry and differential pulse voltammetry were carried out in PBS $(0.1 \mathrm{~mol} / \mathrm{L}$, $\mathrm{pH}=7.0)$ medium. Cyclic voltammetry was carried out on the electrolytic cell without stirring at a scan rate of $100 \mathrm{mV} / \mathrm{s}$ in a voltage range of -0.4 to $0.6 \mathrm{~V}$ at room temperature. Differential pulse voltammetry was obtained by scanning the potential form 0 to 0.4 at room temperature.

\section{RESULTS AND DISCUSSION}

Fig. 1 shows the cyclic voltammograms of polymerization process of poly(erythrosine). As can be seen from the Fig. 1, there is a oxidation peak at $1.6 \mathrm{~V}$ and a reduction peak at -0.6 $\mathrm{V}$, respectively. The peak potential was constant and the peak currents increased with the scanning frequency increasing, but the amplitude decreased with the scanning frequency increasing. Which indicated that the polymer film on the surface of electrode tended to be complete with the polymerization reactions and polymerization and the deposition rated slows down.

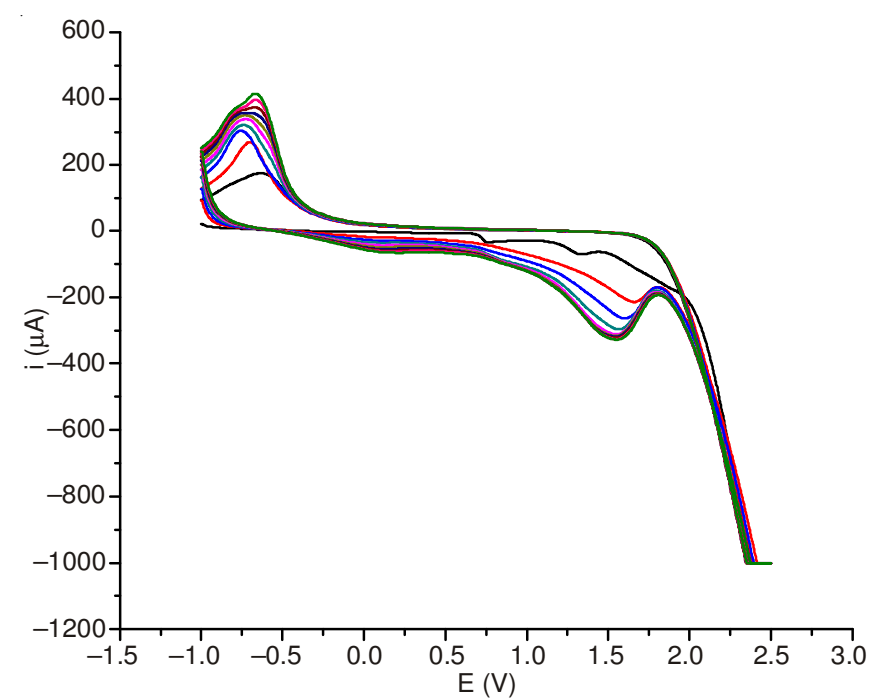

Fig. 1. Cyclic voltammetric curves of P-Ery/GCE/CME in the polymerization process

P-Ery/GCE/CME electrical catalysis: Fig. 2 shows the cyclic voltammetry curves of catechol at the unmodified GCE (curve 1) and P-Ery/GCE/CME (curve 2). At the unmodified $\mathrm{GCE}$, an oxidation peak is observed at $0.23 \mathrm{~V}$ during the anodic sweep from -0.4 to $0.6 \mathrm{~V}$. On the reverse scan, a corresponding reduction peak appears at $0.09 \mathrm{~V}$. So, the peak potential separation $(\triangle \mathrm{EP}=\mathrm{Epa}-\mathrm{Epc})$ is as large as $140 \mathrm{mV}$ at the unmodified GCE, indicating that the electron transfer is slow. The response of catechol shows great difference at the P-Ery/GCE/CME in

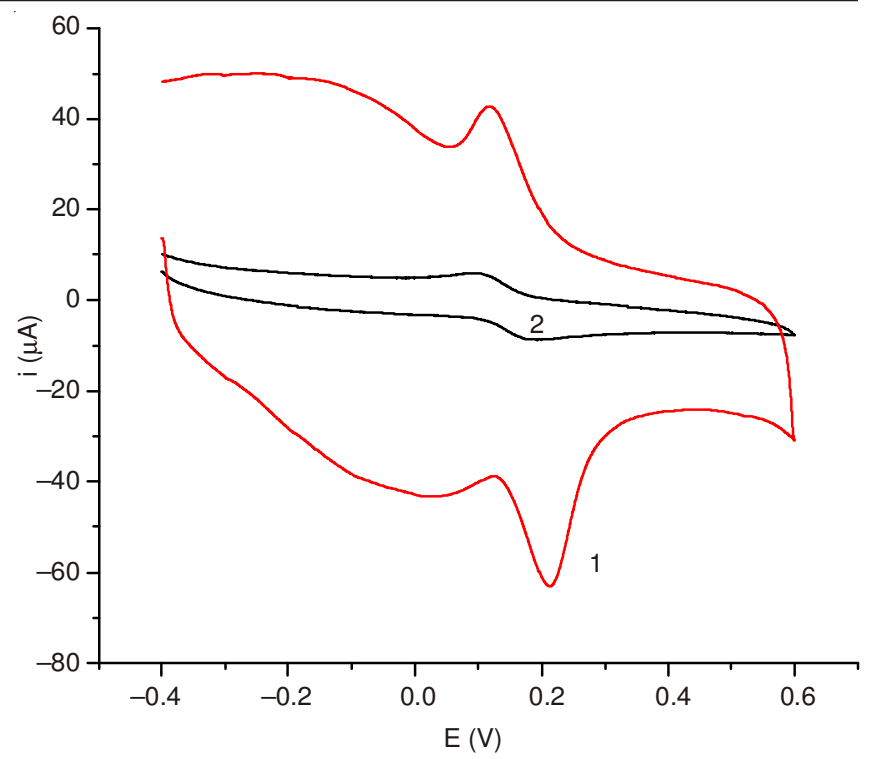

Fig. 2. Cyclic voltammetry curves of $1 \times 10^{-4} \mathrm{~mol} / \mathrm{L}$ catechol at different electrode in PBS (7.0) (1: P-Ery/GCE/CME ;2: GCE)

identical conditions. Firstly, the oxidation peak potential shifts negatively to $0.21 \mathrm{~V}$, while the reduction peak potential shifts positively to $0.12 \mathrm{~V}$. Therefore, the $\Delta \mathrm{Ep}$ is $90 \mathrm{mV}$ at the poly(erythrosine) modified GCE, suggesting that the electrode process of catechol becomes more reversible. Secondly, the oxidation and reduction peak currents significantly increases, revealing that the P-Ery/GCE/CME can greatly improve the determining sensitivity of catechol.

Fig. 3 shows cyclic voltammetric response of the P-Ery/ GCE/CME to catechol solutions of different concentration. It appeared clearly that the oxidation peak current of modified electrode increased rapidly with the concentration of catechol increasing and the peak current presents a good linear relationship with the concentration of catechol in a certain range, indicating that P-Ery/GCE/CME has high catalytic performance for catechol and can be used for the trace detection of catechol.

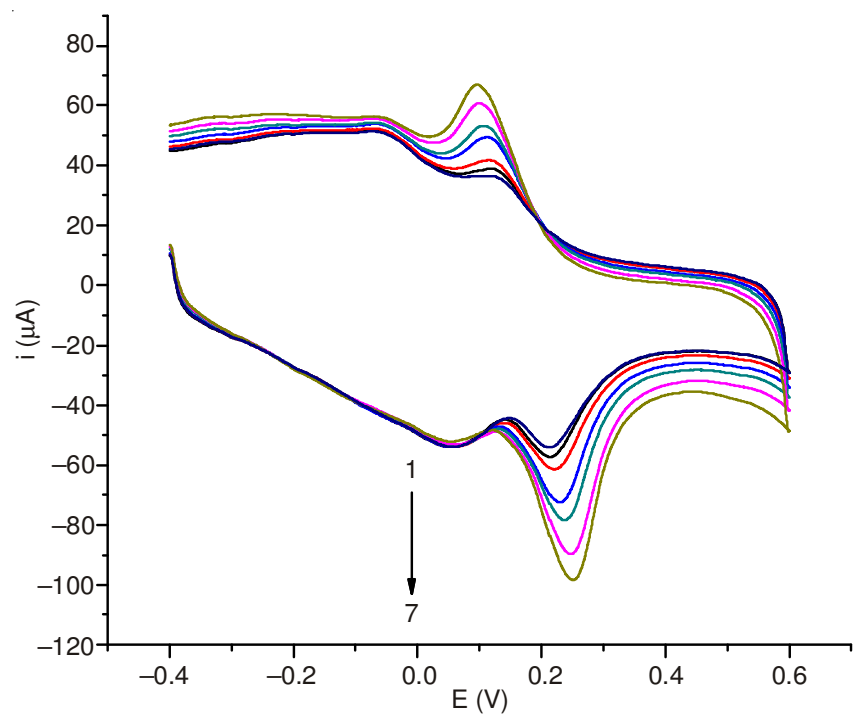

Fig. 3. Cyclic voltammetry curves of Fig. 3 shows $\mathrm{CV}$ response of catechol solutions of different concentration at P-Ery/GCE/CME in PBS (7) $(\mathrm{a} \rightarrow \mathrm{f}: 20,30,40,100,140,200,300 \mu \mathrm{mol} / \mathrm{L})$ 
Selection of the acid: The effects of the solution $\mathrm{pH}$ on electrochemical processes for $1 \times 10^{-4} \mathrm{~mol} / \mathrm{L}$ catechol were also studied using cyclic voltammetric in $\mathrm{NaOH}-\mathrm{KH}_{2} \mathrm{PO}_{4}$ buffer in the $\mathrm{pH}$ range 5.8-8 at catechol sensor. The experimental results showed that the cathodic and anodic peak potentials for catechol shifted negatively as the $\mathrm{pH}$ was increased from 5.8 to 7.8 . It can be seen that the redox peak currents for catechol increased as the $\mathrm{pH}$ is increased from 5.8 to 7 . But at a $\mathrm{pH}$ higher than 7, the redox peak currents decreased with increasing $\mathrm{pH}$. Catechol was easily oxidized by air at higher $\mathrm{pH}(\mathrm{pH}=8)$ and temperature value, so redox peaks of catechol did not appear at $\mathrm{pH}=8$. Overall, the $\mathrm{NaOH}-$ $\mathrm{KH}_{2} \mathrm{PO}_{4}$ buffer ( $\mathrm{pH}$ 7) was chosen as the determination electrolyte (Fig. 4).

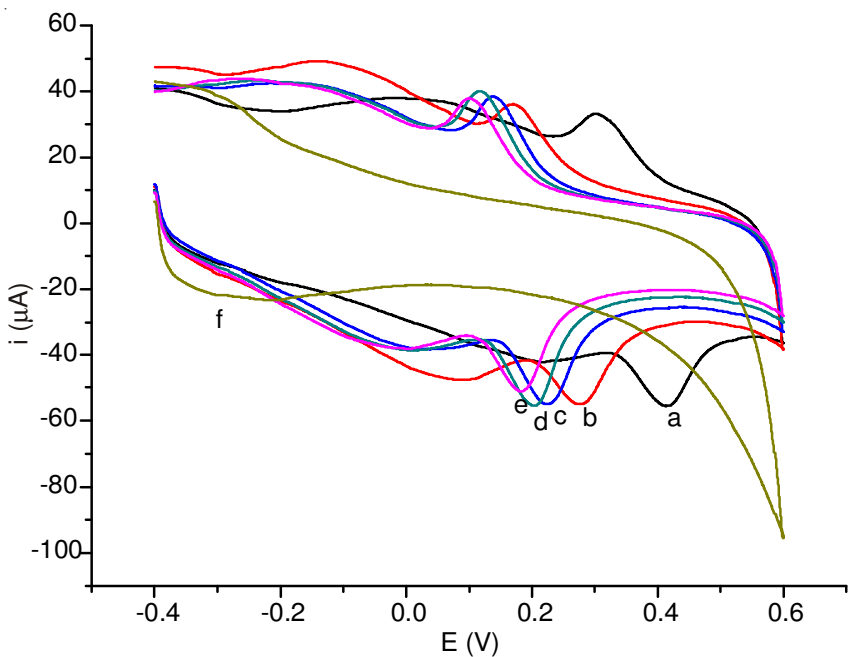

Fig. 4. Cyclic voltammetry curves of the P-Ery/GCE/CME in solution of varying $\mathrm{pH}$ levels in $1 \times 10^{-4} \mathrm{~mol} / \mathrm{L}$ catechol in $0.1 \mathrm{M} \mathrm{PBS}(\mathrm{a} \rightarrow \mathrm{f}: 5.8$, $6.2,6.6,7,7.4,8)$

Effect of scan rates: The effect of scan rates were 50$200 \mathrm{mv} / \mathrm{s}$ at P-Ery/GCE/CME, which was investigated by the cyclic voltammetry and the results showed in Fig. 5a. From the Fig. 5a, as the scan rate increases, the redox peak current increases. Catechol redox peak current and the scan rate showed a good linear relationship. The oxidation and reduction peaks current of catechol present a good linear relationship with the scan rate in the Fig. $5 \mathrm{~b}$. The regression equations is: Ipa $(\mu \mathrm{A})=-0.472-13.95 \mathrm{v}(\mathrm{mV} / \mathrm{s})(\mathrm{R}=0.997), \operatorname{Ipc}(\mu \mathrm{A})=0.343+$ $7.963 \mathrm{v}(\mathrm{mV} / \mathrm{s})(\mathrm{R}=0.998)$ and it indicated that the electrode reaction of catechol at $\mathrm{P}-\mathrm{E}$ ry/GCE/CME was a typical adsorptioncontrolled process.

Linear range and detection limit: In different concentrations of catechol solution, P-Ery/GCE/CME as the working electrode was investigated by DPV in Fig. 6a. under the optimal conditions, the anodic peak current was linear with the value of catechol concentration ranging from $6 \times 10^{-6} \mathrm{~mol} / \mathrm{L}$ to $7 \times$ $10^{-4} \mathrm{~mol} / \mathrm{L}$. The regression equation is Ipa $(\mu \mathrm{A})=-0.002 \mathrm{c}-$ $0.753(\mu \mathrm{mol} / \mathrm{L})\left(\mathrm{R}^{2}=0.996\right)$ and the detection limit was $8 \times$ $10^{-7}(\mathrm{~S} / \mathrm{N}=3)$.

Reproducibility and interference: Under the optimized conditions, P-Ery/GCE /CME was used to determine $1 \times 10^{-4}$ $\mathrm{mol} / \mathrm{L}$ catechol solution for ten times. The RSD is calculated to be $2.5 \%$, revealing that this method for the determination

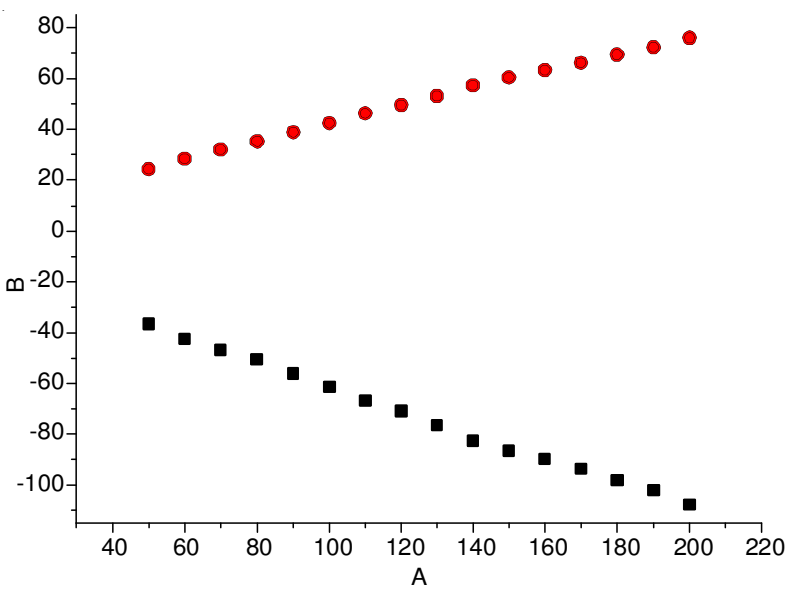

Fig. 5. Cyclic voltammetry curves of $1 \times 10^{-4} \mathrm{~mol} / \mathrm{L}$ catechol at P-Ery/ GCE/CME with different sweep rate; (a) Sweep rate: 50, 60, 70, $80,90,100,110,120,130,140,150,160,170,180,190,200 \mathrm{mV} / \mathrm{s}$; (b) linear relationship of Ip vs. V at P-Ery/GCE/CME

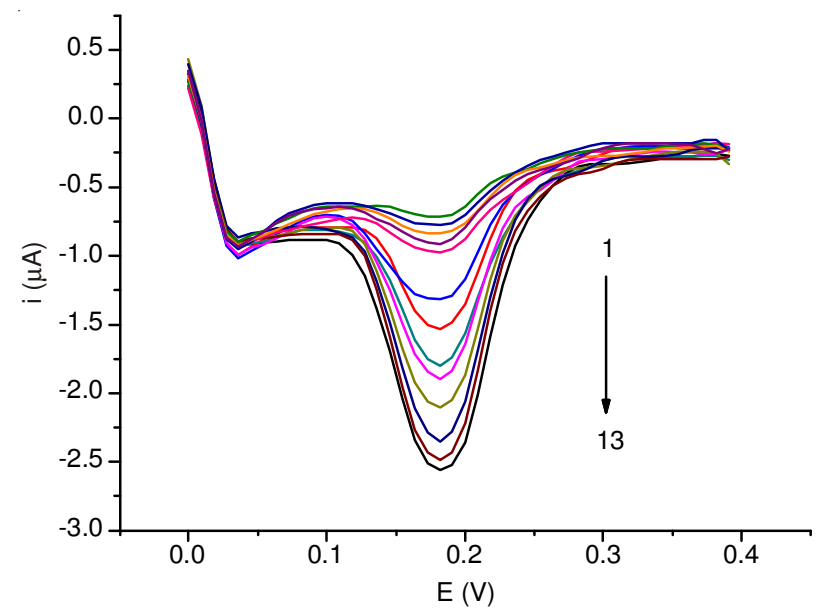

Fig. 6. Differential pulse volatmmetric curves of P-Ery/GCE/CME in PBS(7.0). (c/ $\mu \mathrm{mol} / \mathrm{L}, 1 \rightarrow 13: 6,30,40,60,70,200,280,380,420$, $500,600,680,700)$

of catechol has excellent reproducibility. The interferences of other species on the determination of catechol were examined. It was found that 100 -fold $\mathrm{NO}_{3}^{-}, \mathrm{K}^{+}, \mathrm{Ba}^{2+}, \mathrm{Cl}^{-}, \mathrm{Mg}^{2+}, \mathrm{SO}_{4}{ }^{2-}$, $\mathrm{Na}^{+}, \mathrm{Cu}^{2+}, \mathrm{CrO}_{4}^{-}, \mathrm{Fe}^{2+}, \mathrm{NH}_{4}^{+} ; 20$-fold $\mathrm{Pb}^{2+}, \mathrm{Br}^{-}$; virtually did not interfere with the oxidation signal of $4 \times 10^{-5} \mathrm{~mol} / \mathrm{L}$ catechol at the P-Ery/GCE /CME (peak current change $<5 \%$ ).

Analytical applications: In order to investigate the applications of the developed method for determination of catechol, simulated water samples (containing: $5 \times 10^{-4} \mathrm{~mol} / \mathrm{L}$ $\mathrm{Mg}^{2+}, \mathrm{Pb}^{2+}, \mathrm{Ba}^{2+}, \mathrm{Na}^{+}, \mathrm{NO}_{3}^{-}, \mathrm{Cl}^{-}$) were selected for analysis using the standard adding method. The results are listed in Table-1, the recovery rate was in the range of 99.1-103.2\%, which clearly indicated the applicability and reliability of the modified electrode.

TABLE 1

DETERMINATION RESULTS OF CATECHOL IN WASTE WATER SAMPLES

\begin{tabular}{cclc} 
Sample No. & Added $(\mu \mathrm{M})$ & Found $(\mu \mathrm{M})$ & Recovery $(\%)$ \\
\hline 1 & 10 & 10.32 & 103.2 \\
2 & 50 & 50.55 & 101,1 \\
3 & 80 & 80.43 & 100.5 \\
4 & 120 & 118.94 & 99.1 \\
\hline
\end{tabular}




\section{ACKNOWLEDGEMENTS}

This work was supported by Foundation of Chongqing Municipal Education Commission (Project No. KJ1401114).

\section{REFERENCES}

1. B.G.T. Corominas, M.C. Icardo, L.L. Zamora and J.V.G. Mateo, Talanta, 64, 618 (2004).

2. B. Pranaityt, A. Padarauskas, A. Dikcius and R. Ragauskas, Anal. Chim. Acta, 507, 185 (2004).

3. L. Yao, H. He, Y. Feng and S. Da, Talanta, 64, 244 (2004).

4. D. Allen and Z. El Rassi, J. Chromatogr. A, 1029, 239 (2004).
5. B.P. López and A. Merkoi, Analyst, 134, 60 (2009).

6. L.J. Liu, F. Zhang, F.N. Xi and X.F. Lin, Biosens. Bioelectron., 24, 306 (2008).

7. C.H. Lin, J.Y. Sheu, H.L. Wu and Y.-L. Huang, J. Pharm. Biomed. Anal., 38, 414 (2005).

8. H. Shaopeng, X. Jinrui and W. Qiong, Chinese J. Anal. Chem., 27, 331 (1999).

9. A. Gutes, F. Cespedes, S. Alegret and M. del Valle, Biosens. Bioelectron., 20, 1668 (2005).

10. R.M. de Carvalho, C. Mello and L.T. Kubota, Anal. Chim. Acta, 420, 109 (2000).

11. M.A. Ghanem, Electrochem. Commun., 9, 2501 (2007). 